\title{
Prevention of Child Abuse Through Awareness and Curriculum Design
}

\author{
Noor E. Ain \\ Islamabad Model College for Girls NHC, Federal Directorate of Education Islamabad, Islamabad, Pakistan
}

\begin{abstract}
Child sexual abuse (CSA) means contacts or relations between a child and an adult, i.e., stranger, sibling, parent, or caretaker, when the child is being used as an entity of satisfaction of lust for adult's needs. This research paper highlights the issue of fondling and pornography. Very outrageous facts and figures were derived as from among 460 children 197 (42\%) were found victims of fondling and 16 were the victims both fondling and pornography both. Result showed that fondling and pornography is prevailing in higher ratio in the society as compared to gang rape and sodomy. 4 to 8 years girls and 11 to 14 years boys are at higher risk of fondling. Boys are more prone to pornography as compared to girls. This paper suggested the age appropriate terminologies and vocabulary for teachers and parents to make children aware of the issue and body protection and provided guideline to curriculum developers to add age appropriate content regarding body protection in curriculum.
\end{abstract}

Keywords: abuse, fondling, pornography, good touch, bad touch, good secret, bad secret

\section{Introduction}

Children depend on parents to start their excursion of life. The parents fulfill the child's basic needs such as food, shelter and love. With the passage of time passing through different developmental stages of life he becomes sociable as he interacts with peer and other adults like close blood relatives neighbor and most important teachers. When parents or other adults with a caring responsibility towards children become abusive, the child's essentials change. A growing child is vulnerable to verbal, physical and sexual abuse of various types. We use to talk about verbal and physical abuse their cause and effects but to talk about child sexual abuse is taboo in our society. This is the reason that the ratio of child sexual abuse is increasing in our society.

Child sexual abuse (CSA) or child molestation is a form of child abuse in which an adult or older adolescent uses a child for sexual stimulation. (Child sexual abuse, n.d.)

Child sexual abuse means contacts or relations between a child and an adult, i.e., stranger, sibling, parent, or caretaker, when the child is being used as an entity of satisfaction of lust for adult's needs. Such contacts or interactions are carried out against the child using force, trickery, bribes, threats or pressure (UNICEF, 2001).

Different forms of sexual abuse are:

(1) Assault, including rape and sodomy;

(2) Touching or fondling a child;

Noor E. Ain, M.Phil Education, Vice Principal, Islamabad Model College for Girls NHC, Federal Directorate of Education Islamabad. 
(3) Exhibitionism — forcing a child to exhibit his/her private body parts;

(4) Photographing a child in nude;

(5) Forcible kissing;

(6) Sexual advances towards a child during travel;

(7) Exhibitionism — exhibiting before a child; and

(8) Exposing a child to pornographic materials.

Child abuse occurs in a range of situations, for a range of reasons. Children are rarely subject to one form of abuse at a time.

Sexual abuse has for long been ignored by numerous segments of our society where social standards and cultural anecdotes have played an active role in subduing these issues. These practices have affected the response of law enforcing agencies towards these issues of violence. There are many oppressed segments in the society. However one segment because of its dependence on elders, and has less or no access to resources, stands helpless, i.e., children. Child sexual abuse is rampant all over the world is one of the threats that are persistent in all classes. In Pakistan, children less than 18 years of age become target to CSA at the ratio of 6 children per day. Sexual abuse is observed as disgraceful and not to be discussed and hence hundreds of innocent children survive with the distress of the assault (Sahil, 2011).

As Butt (2015) stated in his article that society closely relates Child sexual abuse cases to concepts of honour, are buried in secrecy. Often the abuser is known to the child, making it more difficult for the families to fight it out in legal battles. The families of the victims decide not to report child abuse cases leading to a scarcity of trustworthy data on this crime. This scarcity of data on child sexual abuse creates the background of disappointment on effective child rights policy. Due to this lack of data, reliable statistics on how many of these sexually active children suffer from health problems is also unobtainable. This is the main reason that there are no operative policies to reach out to these child victims and protect them from further abuse and fatal diseases (Butt, 2015).

Sadruddin in his study on child rights highlighted important issues of children in Pakistan, during 2004-2008. The study exposed that the issues of children were over shadowed in Pakistan during the last few years. The Convention on the Rights of Child did not serve as a definite protector. Education, security and social rights were not given appropriate consideration during the last five years due to which, much operative results were not produced in improving child rights. Though the needs of children and their rights, mainly social and security rights were well understood, but still they were not well addressed, both on social and political podium (Sadruddin, 2011).

Children are the assets of society and their brought up determines the future or success of a country. It is obligatory on the entire society to raise physically and emotionally healthy children. Our children today face various issues such as child labour, physical, sexual and verbal abuse. Perhaps the most serious of these issues is sexual abuse - a chronic crime which does not receive due attention from social or legal circles in Pakistan. Cultural and religious sensitivities create a muted impression about this topic. Our muteness and general delay strengthens the psychological, physical and social significances that sexual abuse has for victims (Perveen, 2016).

According to Dryden (2009), in education today, as in preceding years and surely in coming years child abuse and neglect is and will be a devastating epidemic. Several studies have been conducted and most of them 
found that child abuse and neglect is a conduct that is handed down from generation to generation and only with education we can break this conduct (Dryden, 2009).

Reports and researches indicates the ratio of sodomy gang rape and cases where death caused by sexual assault but the ratio of fondling and pornography is not mentioned in most of the reports as fondling and pornography cases are rarely registered and identified. It is another dilemma or misconception of our society that we consider pay attention to the cases where sodomy and gang rape occurred and do not give heed to fondling exhibitionism and pornography. Whereas every other child is the prey of fondling and exhibitionism in our society and all these things are happening under the carpet.

Prevention education is most effective when it begins early in the learner's educational experience and should include the following elements: teaching skills for self-protection with prospects to practice, instruction in the definitions of abuse and neglect, and the promotion of positive and appropriate interactions between children and adults. A significant element of prevention education is the disclosure and proper reporting of incidents (Tomback, 2010).

It is stated in Pakistan National Education Policy 2009 that detection and prevention of child abuse, shall be infused in the curricula and awareness and training materials shall be developed for students and teachers in this context, keeping in view cultural values and sensitivities (Ministry of Education Pakistan, 2009).

\section{Signs of Child Sexual Abuse}

Children often do not tell about their abuse, so parents should be alert for other signs. These are some signs to watch for:

(1) Physical: Injuries in the genital area, bruises, infections, pain (in genitalia, stomach and head), infections, and bleeding. Sometimes a child shows inapt sexual behaviors like repeated touching of genital parts. According to WHO (2013) unexplained genital injury, vaginal and penile discharge in girls and boys, infection in vagina of girls, bedwetting beyond the usual age, infection in urinary track;

(2) Social indicators: These are signs and symptoms of social dysfunction in a child. The victim becomes isolated from friends, family members and other community members. He/she doesn't participate in social activities like games and social gatherings. Child refuses to meet certain person or refuses to visit certain places without any good reason;

(3) Psychological/behavioral indicators: Sexual abuse has a shocking psychological influence on the child. It generates short term and long term psychological and emotional problems that vary from person to person and situation to situation. Unhappiness-Undue anxiety and crying, sleep disturbances, or loss of appetite. Regression —Behaving like a younger child, thumb sucking, or bed-wetting. Difficulty at school—Sudden drop in grades, behavioral problems, or truancy.

According to Hall and Hall (2011), the short and long term problems includes depression, anxiety, stress, aggression, guilt, self-blaming, powerlessness, low self-esteem, schizophrenia, bipolar disorders and phobias. In all these depression is common and long term problem. "Depression has been found to be the most common long-term symptom among survivors" (Hall, 2011).

The above mentioned are common indicators that children are upset. If present for more than a few days, these indicators could direct that something is wrong and your children need help and parental support. These signs are not an absolute signal of sexual abuse. But if they persist, your children need your help for whatever is bothering them. 


\section{Statement of the Problem}

Ratio of fondling and pornography is higher than sodomy and gang rape of the children but it is highly ignored.

Parents and teachers are not equipped with the proper terminologies according to the mental level of the children to make them aware of body protection.

Curriculum does not cater with content to prevent child abuse.

Emphasis is always on legislation and law enforcement but not on creating awareness among children at an early age regarding body protection to eradicate the root cause.

\section{Objectives}

Following were the objectives of the study:

(1) To highlight the issue of fondling and pornography;

(2) To suggest the age appropriate terminologies for teachers and parents to make children aware of the issue and body protection;

(3) To break the taboo of not discussing body protection with children, among teachers and parents; and

(4) To provide guideline to curriculum developers to add age appropriate content regarding body protection in curriculum.

\section{Methodology}

To probe the issue and statements of the problem of children (age 4 to 14 years), parents and teachers from public and private sector were interviewed. To gain children confidence, teachers were trained to run awareness sessions in their classrooms to find out the victims of fondling and pornography. 460 (230 girls and 230 boys) children participated in awareness session to respect the self-esteem of the children in awareness session children were told if they were suffering from such issues they should discuss their problem with their teachers in privacy and confidentially they should not discuss any of their problem during the session. 10 public and 10 private schools were visited and 100 teachers including head teachers were interviewed. 30 parents belong to different social status were interviewed.

\section{Discussion}

Very outrageous facts and figures were derived as from among 460 children, 197 (42\%) were found victims of fondling and 16 were the victims both fondling and pornography both. Result showed that fondling and pornography is prevailing in higher ratio in the society as compared to gang rape and sodomy.

4 to 8 years girls and 11 to 14 years boys are at higher risk of fondling. Boys are more prone to pornography as compared to girls. In all the cases, fondlers were not strangers for children they were close blood relatives, neighbours, servants, tutor and molvi in relation to children.

Children who had been the victim of fondling and pornography feeling scared telling anyone about the incident. Children are usually told to keep the abuse secret. This could involve threats, bribes, or physical force. Children might feel responsible for the abuse and fear an angry reaction from their parents.

Out of 100 not a single teacher was equipped with age appropriate terminology to aware the children of their body protection. Out of 30 families only 6 families discussed the issue with their kids and suggested them ways for their body protection. 
Majority of the parents and teachers were of the view that discussing this issue with children will snatch their innocence and fill up their minds with filthy thoughts. Moreover they were finding it difficult to discuss the issue with children as it is considering X-rated in the society to discuss gentile area or private body parts with children.

It was pleasing to denote that parents and teachers both wanted to break the taboo but they were not equipped with age appropriate terminologies to make children aware of the issue. Teachers were of the view that curriculum does not make any arrangement at any level to convey the message to the children.

\section{Recommendations}

Following is recommended for parents:

Children's awareness of an abuser's tactics are their best defense. Adults, parents and teachers should tell the children that they can trust you to respond to their concerns about fondling, sexual advances or assaults. This will help to avoid more severe circumstances.

Parents should be alert to grownups who take an over interest in their children. They should frequently ask their children what they did while they were away at school, daycare or camp. They must take time to listen to their children and discuss what to do when susceptible to keep a secret. They must be aware of that you're whom your children like to spend time with and why.

Interaction with kids isn't easy, particularly for difficult subjects like child abuse. Good communication with children will create confidence and help to diminish stress in your relationship. Establish understanding with children. Understanding comes from friendly, honest, face-to-face adult/kid relations. Welcome their suggestions. Laugh at their jokes. Restrain the lectures. Teach decision making. Foster a sense of responsibility for decisions and an understanding of significances. Encourage your child to explain the reasons for their choices to develop their understanding of values.

Pay attention to the unseen needs and feelings of the children. Ask clarifying questions without being annoyed to discover why children have altered patterns or are avoiding people or places. Teach openness - explain the difference between good secrets, bad secrets, good touch, bad touch and confused touch. Help children resolve their own glitches use questions to help your kids recognize issues and appropriate alternatives.

Smile, even if you don't feel like it—Your body language speaks louder than your words and how you say them. Smiling can also help you to gain perspective. Take an earnest attention in their views, their delights and their troubles, their sense of failure and of success.

When a child tells you about abuse/fondling or if any children become victims of abuse, your first response is very significant in helping them through the trouble. Don't panic or overreact to the information victimized child tell you. Don't disapprove him or tell him that he/she misunderstood what happened. Assure your children that they are not to blame for what happened. Appreciate them for telling you about the incident but try to evade repeated nerve-wracking interviews.

Following are the recommendations for teachers:

It is essential that classroom teachers and school counselors be subtle to students' maturity and emotional willingness when dealing with content regarding child abuse. The aim of any instruction on the prevention of child abuse should be not only to update students about facts and teach skills, but also to assimilate information about healthy behaviors and personal responsibility into a wider perspective of living. Students must be cheered to apply what they learn, to practice prevention strategies, and to discuss the issues with their parents, family, and 
friends. It is only through the cooperative efforts of the school and community that incidents of child abuse and neglect will be reduced.

Make your students understand of good, bad, and confusing touches. Help them to identify feelings and physical signs associated with good, bad, and confusing touches. Guide them in identifying private parts of the body as being parts of the body covered by bathing suits. Make them understand that their bodies belong to them, and that they have the right to say no to anyone who touches them in a way that makes them feel uncomfortable. Identify specific people to whom children should go to for help.

Teachers or curriculum developers should develop stories and worksheets to convey the message in age appropriate language.

Following vocabulary is recommended for parents and teachers to convey the message.

(1) Say "No" in a strong voice. Get away to a safe place. Tell a grown-up you can trust.

(2) Good Touch: A touch that feels okay, acceptable, warm, and makes you feel loved. Examples of good touches include hugs, handshakes, high fives, kisses, back scratches, pats on the head/shoulder, and snuggling or cuddling with someone you love.

(3) Bad Touch: A touch that feels bad, uncomfortable, embarrassing, or scary. A bad touch can hurt and can leave a severe bruise, cut, welt, broken bone, or burn.

(4) Confusing Touch: A touch that feels unsafe, mixed-up, or makes you feel uncomfortable. A confusing touch may start out okay but end up not being okay. Examples of confusing touches are bear hugs, tickling, and kisses from someone you do not know or do not feel comfortable around.

(5) Grown-up: An appropriate adult who can help (Parent or relative, teacher, police officer, adult store clerk, adult baby sitter, etc.).

(6) Private: Belonging to one's self; not public.

(7) Private Parts: Parts of the body covered by a bathing suit.

(8) Good Secret: A secret that you feel safe and comfortable keeping because it does not hurt you or anyone else.

(9) Bad Secret: A secret that you feel uncomfortable keeping because it could hurt you or someone else.

This Personal Body Safety - Child Abuse Prevention curriculum should be developed as part of a continuing effort to provide learners with the knowledge and skills required to become contributing members of our society.

Curriculum guide should be developed as one device which teachers can use in the prevention of child abuse. Teachers should be further motivated to discover the broad range of educationally relevant materials relating to this difficult issue. Such accomplishments will increase the knowledge and skills necessary for learners to become safe and useful members of our society.

\section{References}

Butt, Q. (2015). Crime against children. The Express Tribune Pakistan.

Child sexual abuse. (n.d.). Retrieved from wikipedia.

Child sexual abuse. (n.d.). Retrieved September 02, 2015, from wikipedia: en.wikipedia.org/wiki/Child_sexual_abuse Dryden, K. M. (2009, December). Child abuse and neglect. University of Wisconsin.

Hall, M. H. (2011). The long-term effects of childhood sexual abuse. Retrieved August 21, 2016, from American Couselling Association: www.counseling.org

Ministry of Education Pakistan. (2009). National Education Policy 2009. Islamabad: Ministry of Education Pakistan. 
Perveen, S. (2016). Child sexual abuse in Pakistab-A fatal analysis. Journal of Poineering Medical Sciences.

Sadruddin, M. M. (2011, March 31). Study on the important issue of child rights in Pakistan. Retrieved August 20, 2016, from Qurtaba university website: www.qurtaba.edu.pk

Sahil. (2011). Trends in reported cases of child sexual abuse a five year analysis 2007-20011. Islamabad: SahilI.

Tomback, R. M. (2010). Personal body safety-Child abuse and neglect prevention curriculum. Maryland: Hardford County Public Schools. 